\title{
Double-Position-Boundaries Free 3C-SiC Epitaxial Layers Grown on On-Axis 4H-SiC
}

\author{
Xun Li, Henrik Jacobson, Alexandre Boulle, Didier Chaussende and Anne Henry
}

\section{Linköping University Post Print}

\section{Tweet}

N.B.: When citing this work, cite the original article.

Original Publication:

Xun Li, Henrik Jacobson, Alexandre Boulle, Didier Chaussende and Anne Henry, DoublePosition-Boundaries Free 3C-SiC Epitaxial Layers Grown on On-Axis 4H-SiC, 2014, ECS Journal of Solid State Science and Technology, (3), 4, P75-P81.

http://dx.doi.org/10.1149/2.012404jss

Copyright: Electrochemical Society

http://www.electrochem.org/

Postprint available at: Linköping University Electronic Press

http://urn.kb.se/resolve?urn=urn:nbn:se:liu:diva-106298 


\section{Double-position-boundaries free 3C-SiC epitaxial layers grown on on-axis $\mathbf{4 H - S i C}$}

Xun Li, ${ }^{\text {a,z }}$ Henrik Jacobson, ${ }^{\text {b Alexandre Boulle, }}{ }^{\mathrm{c}}$ Didier Chaussende, ${ }^{\mathrm{d}}$ and Anne Henry

a Department of Physics, Chemistry and Biology, Semiconductor Materials Division, Linköping University, SE-581 83 Linköping, Sweden

bISV, Linköping University, SE-601 74, Norrköping, Sweden

'Siences des Procédés Céramiques et de Traitements de Surface, CNRS UMR7315, Centre Européen de la Céramique, 12 rue Atlantis, 87068 Limoges Cedex, France

${ }^{\mathrm{d}}$ LMGP, CNRS, Grenoble INP, 3 parvis Louis Neel, 38016 Grenoble, France

'Department of Physics, Chemistry and Biology, Thin Film Physics Division, Linköping University, SE-581 83 Linköping, Sweden

zE-mail: xunli@ifm.liu.se 


\section{ABSTRACT}

High quality double-position-boundaries free 3C-SiC epilayers have been successfully grown on on-axis (0001) 4H-SiC by chemical vapor deposition at optimized conditions as observed with optical microscopy and X-ray diffraction. The effect of the growth parameters, including temperature, $\mathrm{C} / \mathrm{Si}$ ratio, ramp-up condition, $\mathrm{Si} / \mathrm{H}_{2}$ ratio, $\mathrm{N}_{2}$ addition and pressure, on the quality of the grown layers is investigated. Different techniques, including microscopic and spectroscopic techniques, are used to characterize the epilayers. High resolution X-ray diffraction shows $2 \theta-\omega$ curve with full width at half maximum of only 16 arcsec for the (111) reflection detected from a $35 \mu \mathrm{m}$ thick 3C-SiC layer, showing the good structural quality of the layer. Reciprocal space maps confirm the absence of double-position-boundaries in a large depth of the layers. Low temperature photoluminescence measurement shows clear near-band gap emission with sharp and single peaks, which further verifies the high quality of the epilayers. 


\section{Introduction}

Among the most common SiC polytypes, $3 \mathrm{C}$-SiC is the only one with a cubic structure; it is thus an extremely interesting material for fundamental solid-state physics investigations and of exceptional potential for various applications. Its superior properties over the other SiC polytypes and other semiconductors are high electron mobility ${ }^{1}$, good electron drift velocity ${ }^{2}$ and lower interface trap density with oxide ${ }^{3}$, which will be beneficial for MOSFET and HEMT devices. It can also be used for MEMS application due to its hardness ${ }^{4}$.

The growth of 3C-SiC on Si substrates by chemical vapor deposition (CVD) has been studied intensively since last century due to Si wafers combining both low cost and large diameters. In addition, the direct use of standard silicon processing lines would be possible. However, this approach has shown its own limitation due to the big mismatches of both materials, Si and 3C$\mathrm{SiC}$, in thermal expansion coefficients (8\%) and lattice constants $(20 \%)$. The obtained 3C-SiC epilayers have poor crystalline quality and encounter a very high density of defects, such as voids, stacking faults and anti-phase domains, which appeared as incompatible with any electronic device. Most of the work has been conducted on (001) Si substrates leading to (001) 3C-SiC layers. The (111) oriented 3C-SiC, which is a suitable substrate for hexagonal nitrides growth, has severe cracking and warping problems when grown on (111) Si substrate compared to the (001) oriented heteroepitaxial system ${ }^{5}$. Experimental works using other orientations and/or off-cut substrates have also been reported. For instance, a decrease of the stacking faults density has been noted when using (211) Si substrate on which $3 \mathrm{C}$-SiC crystal can grow with a step-flow mode ${ }^{6}$ Using $\alpha-\mathrm{SiC}$ substrates, growth of higher quality $3 \mathrm{C}$ epilayers could be achieved not only by $\mathrm{CVD}^{7,8}$, but also by continuous-feed physical vapor transport $(\mathrm{CF}-\mathrm{PVT})^{9}$, vapor-liquid-solid (VLS) ${ }^{10}$, topseeded solution growth technique $(\mathrm{TSSG})^{11}$ and sublimation epitaxy technique ${ }^{12}$. However, the 
defect called double positioning boundary (DPB), a particular case of twin boundary, is present when using $\alpha-\mathrm{SiC}$ substrates. This is mainly due to the fact that $3 \mathrm{C}$ has two types of stacking sequence with a $60^{\circ}$ rotation difference (i.e. $\mathrm{ACB}$ and $\mathrm{ABC}$ ) when grown on the basal plane of a hexagonal polytype.

The elimination of DPBs has been studied by many groups. 3C layers grown on low-tilt-angle vicinal Si-face $6 \mathrm{H}$ substrates by CVD have been found to contain less DPBs than those on Cface ${ }^{13}$. Soueidan et al. ${ }^{14}$ have successfully grown DPBs free $3 \mathrm{C}$-SiC layers on on-axis Si-face $4 \mathrm{H}$ and $6 \mathrm{H}$ substrates and also on $3.5^{\circ}$ off Si-face $6 \mathrm{H}$ substrates using VLS methods with Si-Ge melts, however, reproducibility issues are mentioned. Using substrates as $4^{\circ}, 8^{\circ}$ off $\mathrm{Si}$-face $4 \mathrm{H}$ or on-axis C-face $6 \mathrm{H}, 3 \mathrm{C}$ epilayers with DBPs are always obtained. Less DPBs were shown to emerge for epilayers grown on $15 \mathrm{R}$ substrates compared with films grown on $6 \mathrm{H}-\mathrm{SiC}^{15,16}$. The growth of DPBs-free $3 \mathrm{C}-\mathrm{SiC}$ on patterned $4 \mathrm{H}$ substrates, using both $\mathrm{VLS}^{17}$ and $\mathrm{CVD}^{18}$, has also been reported. However, this method needs precise lithography and dry etching technique for substrate preparation and only small area free of DPBs are obtained, typically around $200 \times 200 \mu \mathrm{m}^{2}$. Using TSSG technique DPBs-free 3C layers were obtained only on $6 \mathrm{H}-\mathrm{SiC} 4^{\circ}$ off-cut oriented toward the [1-100] direction ${ }^{11}$. The model discussed for the elimination of DPB is based on anisotropic lateral expansion of the two $3 \mathrm{C}$ domains and was first proposed by Latu-Romain et al. ${ }^{19}$. More recently using Monte-Carlo simulations, the possibility to obtain DPBs-free 3C epilayers has been predicted only on misoriented $6 \mathrm{H}$ substrates with large miscut $\left(\sim 8^{\circ}\right.$ was proposed but towards [1120]), for on-axis substrates (both $6 \mathrm{H}$ and $4 \mathrm{H}$ ) a random distribution of large 3C-SiC domains should appear and for the growth on $4 \mathrm{H}-\mathrm{SiC}$ substrates with large miscut, dislocations would degrade the layer quality ${ }^{20}$. It is worth noting that the largest sample free of DPB reported to date has been obtained by the CF-PVT method and is a $30 \mathrm{~mm}$ diameter free-standing (111) 3C-SiC 
layer grown on an on-axis substrate ${ }^{21}$. Again, serious reproducibility problems are mentioned. To our knowledge, all the reported attempts to grow DPB-free epilayers by standard CVD have always been unsuccessful.

In this paper, we report the CVD growth of high quality $3 \mathrm{C}-\mathrm{SiC}$ epilayers on $4 \mathrm{H}-\mathrm{SiC}$ nominally on-axis substrates with large single domain area. The experimental procedures are described in Section II. Results regarding the effect of various growth parameters on the morphology of the obtained layers are displayed in Section III. Section IV gives more detailed characterization information and in section $\mathrm{V}$ a discussion and a tentative description of the growth process are presented.

\section{Experimental}

All the $3 \mathrm{C}-\mathrm{SiC}$ epilayers were grown in a horizontal hot-wall CVD reactor without rotation and with standard chemistry using silane $\left(\mathrm{SiH}_{4}\right)$ and propane $\left(\mathrm{C}_{3} \mathrm{H}_{8}\right)$ as precursors. The substrates are commercial n-type doped on-axis $4 \mathrm{H}-\mathrm{SiC}(0001)$ with unintentional tilt angle of less than $0.08^{\circ}$ as specified by the supplier. All the samples, which have been cut into the size of about $2 \times 2 \mathrm{~cm}^{2}$, are from wafers in the same boule. Si-face is chosen for this study in order to get lower net doping concentration in the grown layer. Hydrogen and $\operatorname{argon}\left(5 \%\right.$ of $\mathrm{Ar}$ in $\left.\mathrm{H}_{2}\right)$ were used as carrier gases. All the growth runs began with a heating procedure from room temperature to a certain stabilization temperature and then stayed at this temperature for $10 \mathrm{~min}^{22}$. This stabilization temperature was generally set at $1250^{\circ} \mathrm{C}$, but could be slightly lower depending on the growth temperature. Then the susceptor was further heated to the growth temperature. A reduced process pressure, typically $200 \mathrm{mbar}$, was used. 
At the early stage of our experiments, a small amount of nitrogen gas $(\mathrm{N} / \mathrm{C}=0.32 \%)$ was always added into the chamber during the growth procedure. The introduction of $\mathrm{N}_{2}$ has been always prior that of $\mathrm{SiH}_{4}$. This was due to a previously reported work ${ }^{23}$ : adding $\mathrm{N}_{2}$ impurities could increase $\mathrm{C}$ vacancies and help to stabilize cubic polytype. This is especially useful when the conditions are not suitable for the 3C-SiC growth. The optimization of several process parameters (temperature, $\mathrm{C} / \mathrm{Si}$ ratio, ramp-up condition and pressure) is presented in this work. Reproducibility of the results has not been tried when the growth conditions were not optimized. However, when the process parameters are well defined and controlled to achieved DPB free layers, results could have been repeated for at least three times.

The morphology and surface roughness of the layers were investigated by Nomarski differential interference contrast (NDIC) optical microscopy and tapping mode atomic force microscopy (AFM). The crystalline quality of the grown epilayers was analyzed by (1) low temperature photoluminescence (LTPL) at $2 \mathrm{~K}$ in a bath cryostat using $351 \mathrm{~nm} \mathrm{Ar}{ }^{+}$laser line for excitation; (2) high resolution X-ray diffraction (HRXRD). Triple-axis measurements were employed to $\omega$ rocking curves and $2 \theta-\omega$ diffraction curves. On the primary side a Ge (220) crystal monochromator was used. The secondary side had a Ge (220) triple-bounce collimator crystal that limits the acceptance into the detector to less than 12 arcsec; (3) electron back scattering diffraction (EBSD). The thickness of the 3C-SiC layers was measured by Fourier Transform Infrared (FTIR) reflectance. The net doping concentration was determined by Hg probe capacitance-voltage (CV) method at room temperature. 


\section{Growth results and discussion}

The growth temperature and $\mathrm{C} / \mathrm{Si}$ ratio are probably the two most important process parameters which are influencing the growth process and therefore the results. They are also closely related to each other since the decomposition of $\mathrm{SiH}_{4}$ and $\mathrm{C}_{3} \mathrm{H}_{8}$ are temperature dependent. Their effect on the morphology and crystalline quality of the obtained films is presented here. Then the surface preparation of the substrate either during temperature ramp-up or at the growth temperature but prior to the growth is reported. The growth rate effect on the crystal quality of the layer is also investigated. Results from growth done at various pressures are also described. Finally, comparison when using (0001) 6H-SiC as substrate is presented.

\section{III.1. Temperature effect}

The growth temperature was varied between $1200^{\circ} \mathrm{C}$ and $1400^{\circ} \mathrm{C}$ using the same C-rich ramp-up conditions. Figure 1 shows the surface morphology of 3C epilayers grown with a fixed pressure of $200 \mathrm{mbar}, \mathrm{C} / \mathrm{Si}=1, \mathrm{Si} / \mathrm{H}_{2}=0.02 \%$ and $\mathrm{N} / \mathrm{C}=0.32 \%$. When the temperature is $1325^{\circ} \mathrm{C}$ or even lower, the surface of the layers appears very dark as shown in Fig. 1a. The deposit, analyzed by $\mu$ Raman shows only strong signal associated to both Si and 3C-SiC. No carbon related peak could be observed. Further XRD measurement reveals polycrystalline structure for both $\mathrm{Si}$ and $3 \mathrm{C}-\mathrm{SiC}$. A temperature of $1350^{\circ} \mathrm{C}$ is found to be the most favorable one to grow uniform layer without any DPBs (Fig. 1b). At higher growth temperature, typically $1375^{\circ} \mathrm{C}$ some small DPBs are observed (Fig. 1c) giving rise to a global surface morphology degradation when the temperature is further increased (Fig. 1d). Note that the growth rates are respectively of $4.9 \mu \mathrm{m} / \mathrm{h}, 5.9 \mu \mathrm{m} / \mathrm{h}$ and $5.6 \mu \mathrm{m} / \mathrm{h}$ for a temperature of $1350{ }^{\circ} \mathrm{C}, 1375{ }^{\circ} \mathrm{C}$ and $1400^{\circ} \mathrm{C}$. For this latter temperature of $1400^{\circ} \mathrm{C}$, 
decreasing the $\mathrm{Si} / \mathrm{H}_{2}$ ratio from $0.02 \%$ to $0.015 \%$ decreases the growth rate to $4.7 \mu \mathrm{m} / \mathrm{h}$ as expected, but the layer still remains polycrystalline.

\section{III.2. C/Si ratio effect}

At the growth temperature of $1350^{\circ} \mathrm{C}$, good surface morphology of the $3 \mathrm{C}$ layers could be obtained only when using a $\mathrm{C} / \mathrm{Si}$ ratio in a narrow range close to 1 . With $\mathrm{Si}$-rich conditions $(\mathrm{C} / \mathrm{Si} \leq 0.9)$, silicon condenses on the $\mathrm{SiC}$ surface, forming Si hillocks which look like solidified Si droplets. Such hillocks are shown in Fig. 2a, from a sample grown at $1350{ }^{\circ} \mathrm{C}$, with $\mathrm{C} / \mathrm{Si}=0.9, \mathrm{Si} / \mathrm{H}_{2}=$ $0.022 \%$. After wet chemical etching in a $\mathrm{HNO}_{3}: \mathrm{HF}: \mathrm{CH}_{3} \mathrm{COOH}(5: 3: 3)$ solution, most of the $\mathrm{Si}$ hillocks vanished (Fig. 2c). The remaining surface is relatively smooth. No crater or depth perturbation of the surface was revealed which would suggest that the Si clusters are present only on the top surface of the layer, not through the epilayer. Note that the silane flux is switched off before cooling down. For $\mathrm{C}$-rich conditions $(\mathrm{C} / \mathrm{Si}>1.1)$, the quality of the epilayers degrades compared to when using a $\mathrm{C} / \mathrm{Si}=1$ (see Figure $2 \mathrm{~b}$ in comparison with Fig. 1b). The surface is very rough and DPBs and other types of defect appear on the surface.

\section{III.3. Temperature ramp-up conditions}

When both precursors $\mathrm{SiH}_{4}$ and $\mathrm{C}_{3} \mathrm{H}_{8}$ were introduced directly at the growth temperature, DPBs were always observed. Si-rich condition during temperature ramp-up or prior the growth was not tested since it is known to stabilize the $4 \mathrm{H}$ polytype for the growth on nominally on-axis $4 \mathrm{H}-\mathrm{SiC}$ substrate, but at a much higher temperature than used in this study ${ }^{24,25}$. Thus, two different temperature ramp-up conditions have been tested. All these ramp-up conditions are followed by the same growth step, experiments were done at $200 \mathrm{mbar}, 1350{ }^{\circ} \mathrm{C}, \mathrm{C} / \mathrm{Si}=1, \mathrm{Si} / \mathrm{H}_{2}=0.015 \%$. 
The growth time differs from one experiment to another and is comprised between $1 \mathrm{~h}$ and $4 \mathrm{~h}$, the growth rate of $4 \mu \mathrm{m} / \mathrm{h}$ being similar.

- In the first case, the $\mathrm{C}_{3} \mathrm{H}_{8}$ precursor was introduced into the reactor from room temperature. Once the growth temperature was reached, the $\mathrm{C}_{3} \mathrm{H}_{8}$ flow was set to the growth flow before the introduction of $\mathrm{SiH}_{4}$ in the gas mixture. During this first step of heating up, various $\mathrm{C}_{3} \mathrm{H}_{8}$ flows were tested (Fig. 3). Without $\mathrm{C}_{3} \mathrm{H}_{8}$ flow or if the flow is too small compared to the growth flow, the morphology of the layer is characterized by a high density of DPBs. If the same flow is used during temperature ramp-up and growth, the grown $3 \mathrm{C}-\mathrm{SiC}$ epilayers are single domain (Fig. 3a). But if the flow is too high (typically higher than the growth flow), the material quality is degraded and many defects are observed (Fig. 3b). With further increasing of the $\mathrm{C}_{3} \mathrm{H}_{8}$ flow to the maximum allowed by the system, the sample surface is again covered by DPBs (Fig. 3c).

- In the second case, surface preparation in C-rich atmosphere was investigated by having a $\mathrm{C}_{3} \mathrm{H}_{8}$ flow through the susceptor at the growth temperature before introducing $\mathrm{SiH}_{4}$. In this case, the temperature ramp-up is performed under $\mathrm{H}_{2}$ ambient (with 5\% Ar) and once the growth temperature is reached, a $0.015 \% \mathrm{C}_{3} \mathrm{H}_{8}$ in $\mathrm{H}_{2}$ treatment is conducted prior the growth with varying times: $0 \mathrm{~min}, 5 \mathrm{~min}$, and $15 \mathrm{~min}$ (Fig. 3d-f). As already mentioned, many DPBs were observed when the growth started directly after the heating stage, i.e. for a C-rich treatment time of 0 min (Fig. 3d). After a 5 min treatment only, the epilayer surface exhibits a smooth morphology without any DPB (Fig. 3e). The observed stripe features are usually related to the emergence of stacking faults to the surface. For a longer treatment time (15 min), the epilayer contains a high density of DPBs (Fig. 3f). 


\section{III.4. Growth rate}

A set of experiments was carried out to study the influence of the average growth rate on the occurrence of DPB-free layers. As expected, the growth rate almost linearly increases with the $\mathrm{Si} / \mathrm{H}_{2}$ ratio (Fig. 4), when keeping the other growth parameters constant. According to the trend given by the fit line, the growth rate has a negative value when $\mathrm{Si} / \mathrm{H}_{2}=0$ corresponding to a small etching rate by hydrogen of $0.02 \mu \mathrm{m} / \mathrm{h}$. When the $\mathrm{Si} / \mathrm{H}_{2}$ ratio is below $0.019 \%$, the surface of the 3C-SiC layers is basically as good as shown in Fig. $1 \mathrm{~b}$ or $3 \mathrm{e}$, i.e. with single domain layer, only if one of the correct ramp-up conditions is applied. When using higher $\mathrm{Si} / \mathrm{H}_{2}$ ratio, either a high density of Si hillocks was observed on the layer surface or the epilayer has a polycrystalline structure.

\section{$\underline{\text { III.5. Pressure effect }}$}

Different process pressures, from 200 mbar up to 500 mbar, have also been investigated, keeping the other growth parameters similar i.e. $1350^{\circ} \mathrm{C}$, with $\mathrm{C} / \mathrm{Si}=1$ and $\mathrm{Si} / \mathrm{H}_{2}=0.015 \%$. The growth rates are almost the same considering the measurement deviation, about $4.5 \mu \mathrm{m} / \mathrm{h}$ for $300 \mathrm{mbar}$ and $500 \mathrm{mbar}, 4.6 \mu \mathrm{m} / \mathrm{h}$ for $400 \mathrm{mbar}$. These values are slightly higher compared to the growth rate obtained at $200 \mathrm{mbar}(4.2 \mu \mathrm{m} / \mathrm{h})$. This is supposed to be due to an enhanced etching at low pressure which reduces slightly the growth rate. The layers grown at a pressure higher than 200 mbar were not totally single domain, however very large single domains (more than $200 \times 200 \mu \mathrm{m}^{2}$ ) have been observed with the optical microscopy. Effect of pressure has not been studied much deeper but according to the results obtained, DPB-free layers should also be obtained by slightly tuning the working conditions. Nevertheless, the hydrogen etching, which is more important at 
lower pressure, could favor the preparation of the surface for optimal growth. And a low pressure (typically of 200 mbar) gave pretty good results.

\section{III.6. Comparison with $3 \mathrm{C}$ on $6 \mathrm{H}$}

The growth of $3 \mathrm{C}-\mathrm{SiC}$ on on-axis $\mathrm{Si}$-face $6 \mathrm{H}-\mathrm{SiC}$ substrates has been done in the same CVD reactor using the optimized process for DPB free $3 \mathrm{C}-\mathrm{SiC}$ epilayer on $4 \mathrm{H}-\mathrm{SiC}$ as a starting point. Different morphology was observed and results were generally not as good as for epilayers grown on $4 \mathrm{H}$ substrates (the sample in Fig. 5 was grown at $1350{ }^{\circ} \mathrm{C}, 200 \mathrm{mbar}, \mathrm{C} / \mathrm{Si}=1, \mathrm{Si} / \mathrm{H}_{2}=0.015 \%$ and with moderate C-rich ramp-up condition). The epilayer is $100 \% 3 \mathrm{C}$ but with some DBPs and triangular defects. When the growth temperature is decreased to $1325^{\circ} \mathrm{C}$, Si hillocks are observed on the layer surface. While increasing the temperature to $1375^{\circ} \mathrm{C}$, the epilayer is found to have only about $40 \% 3 \mathrm{C}$, meaning that homo-epitaxy $(6 \mathrm{H}$ on $6 \mathrm{H})$ appears for the other $60 \%$ of the surface. At $1400{ }^{\circ} \mathrm{C}$, almost $100 \% 6 \mathrm{H}$ was epitaxially grown. As in the case when using nominally on-axis $4 \mathrm{H}-\mathrm{SiC}$ substrates, epilayers grown with low $\mathrm{C} / \mathrm{Si}(\leq 0.9)$ have a top surface covered by $\mathrm{Si}$ clusters, whereas epilayers grown with high $\mathrm{C} / \mathrm{Si}(\geq 1.3)$ have a polycrystalline structure. Surface preparation with $\mathrm{C}$ rich ambient prior the growth is also found a necessary condition to stabilize the $3 \mathrm{C}$ polytype and obtain large domains as observed in Fig. 5.

\section{Detailed characterization}

\section{IV.1. Further morphology characterization with AFM}

Figure 6a shows an image of a typical boundary between two domains for a $20 \mu \mathrm{m}$ thick epilayer. This boundary is actually a shallow groove and depending on the location on the sample, the 
groove depth varies from $45 \mathrm{~nm}$ to $87 \mathrm{~nm}$ for a $20 \mu \mathrm{m}$ thick epilayer and could be as deep as 120 $\mathrm{nm}$ for thicker layers. The surface roughness of the smoother samples as shown in Fig. 3e is typically between 3 and $8 \mathrm{~nm}$ (RMS value) over a 50x50 $\mathrm{m}^{2}$ area. When applied to a small area of $10 \times 10 \mu \mathrm{m}^{2}$, it decreases to less than $1 \mathrm{~nm}$ (Fig. 6b). On this AFM picture, stripe features similar to those observed with optical image (Fig. 3e) are also observed. The highest step measured on this sample surface is less than $5.5 \mathrm{~nm}$. The visualization of these stripe features is further enhanced after $\mathrm{KOH}$ etching (Fig. 6c) and well defined triangular shapes can be observed which are associated to stacking faults. From this picture staking faults density can be determined, typically in the $2 \cdot 10^{4}$ to $5 \cdot 10^{4} \mathrm{~cm}^{-1}$ range.

\section{IV.2. Structural analysis}

As already mentioned, Figure 3e shows a typical surface morphology of a DPB-free sample. EBSD measurement, which is based on weak diffraction pattern and shows orientation and phase of the crystal, was applied to almost the whole sample. The scan confirmed that there is only one $3 \mathrm{C}$ domain for this layer. With statistical treatments, the confidence index was calculated to be close to $100 \%$ with the exception of the position close to one downfall particle. However it should be noted that the penetration depth of EBSD technique is only a few tens of nanometers. So this technique can be seen as a surface technique and further investigations should be done to access more information on the complete layer and not only top surface.

In order to further evaluate the structure quality of the 3C layer more deeply, HRXRD was performed. Reciprocal space maps (RSM) of either the (113) or (111) reflection have confirmed the absence of DPB in a large depth of our 3C-SiC layers. As an example for the sample with thickness of $12.5 \mu \mathrm{m}$ (same as Fig. 3e), the percentage of the presence of a second domain was 
evaluated to be less than $0.1 \%$. This is determined from the intensity recorded from the (113) reflection peak or RSM map as shown in Fig. $7 \mathrm{a}$ and $7 \mathrm{~b}$. When rotating the sample with $60^{\circ}$ around its symmetry axis the intensity of the diffraction changes from maximal value to almost zero. We should notice here that the penetration depth (with the 1/e attenuation criterion) of the X-rays for the (113) reflection is about $8 \mu \mathrm{m}$. We could thus expect that either the layer was with single domain from the interface layer/substrate $(3 \mathrm{C} / 4 \mathrm{H})$, or due to the growth mechanism less than $5 \mu \mathrm{m}$ are needed to convert layer containing DPB to single domain layer. However, with RSM of the (111) reflection peak as shown in Fig. 7c no symmetry is observed around the [111] direction. This confirms in this case that the DPB free layer can be obtained directly from the nucleation stage meaning at the interface layer/substrate since the penetration of the X-rays is $22 \mu \mathrm{m}$ for this direction. In the RSM of the (111) peak, additional features (diffuse streaks) associated to stacking faults are also visualized; they correspond to SFs lying in the (-111) plane (for the streak with an angle of $70^{\circ}$ ) and stacking faults lying in the (11-1) and (1-11) planes (for the streak with an angle of $55^{\circ}$ ). The stacking faults density can be evaluated from the intensity of these streaks ${ }^{26}$ and is found to be in the $1-2 \times 10^{4} \mathrm{~cm}^{-1}$ range.

Figure $8 \mathrm{a}$ is a typical $2 \theta-\omega$ curve collected from (111) Bragg reflection for a $35 \mu \mathrm{m}$ thick $3 \mathrm{C}-\mathrm{SiC}$ epilayer. As mentioned the penetration depth of the X-rays is expected to be $22 \mu \mathrm{m}$ at this reflection and the footprint size used in the measurement is typically $1 \times 1.7 \mathrm{~mm}^{2}$. The reflection peak has a full width at half maximum (FWHM) of 16 arcsec. For the relatively thick layer, this indicates that the strain along the c-axis is low in the $22 \mu \mathrm{m}$ top layer. FWHM values of rocking curves reported in the literature are generally very high for $3 \mathrm{C}$ layers grown on $6 \mathrm{H}$ substrates with few hundred of $\operatorname{arcsec}^{27}$, to the best of our knowledge. Recently, a value of $32 \operatorname{arcsec}$ of the (111) reflection peak was reported for a $760 \mu \mathrm{m}$ thick $3 \mathrm{C}$ layer, which was grown on a low off-cut angle $6 \mathrm{H}$ substrate ${ }^{28}$. 
In addition a FWHM value of 78 arcsec has been measured for the (002) reflection rocking curve from thick 3C-SiC freestanding layers grown by sublimation method using CVD-grown 3C seeds $^{29}$. We observe similar FWHM value (72 arcsec) for our $35 \mu \mathrm{m}$ 3C-SiC epilayer (Fig. 8b), however, this (002) reflection spectrum consists of an overlapping of many sharp peaks with FWHM of only few arcsec. A few of the observed peaks with low intensity and random pattern on the both sides of the more intense peaks could be related to noise. But the stronger and sharper peaks are definitively not noise due to their intensity is much higher than the square root of the total intensity. From this observation, sub-domains, which are with the same stacking sequence, are proposed to exist between the staking faults observed with optical microscopy and AFM. The sub-domains are slightly tilted one to each other with angles in the 0.003 to 0.02 degrees range. As their FWHM is extremely small (less than 5 arcsec) their crystalline quality is extremely high. The $\omega$ curves reported in the literature are generally smooth which could be due to either lower resolution during the experiments, or due to bending of the layer or mosaicity which results to a broadening of the $\omega$ peak. The lowest FWHMs reported for our samples are additional proofs of the high quality of the layer.

\section{IV.3. Electrical and optical properties}

The net donor concentration is about $5 \times 10^{16} \mathrm{~cm}^{-3}$ for most of the slightly doped samples with N/C $=0.32 \%$ as measured by $\mathrm{CV}$ measurements at room temperature. For the undoped samples, the doping concentration could decrease to $2 \times 10^{16} \mathrm{~cm}^{-3}$. This residual doping level is comparable to those obtained when $3 \mathrm{C}-\mathrm{SiC}$ layers are grown on $\mathrm{Si}$ substrate $^{30}$. Using chloride-based chemistry for the growth ${ }^{7}$, the net carrier concentration of $3 \mathrm{C}-\mathrm{SiC}$ layers grown on $6 \mathrm{H}-\mathrm{SiC}$ substrate could 
achieve mid $10^{15} \mathrm{~cm}^{-3}$. This lowest residual doping is probably due to higher growth rate, typically $10 \mu \mathrm{m} / \mathrm{h}$ obtained with chloride based chemistry.

LTPL has been performed at $2 \mathrm{~K}$ on many samples using excitation of the $351 \mathrm{~nm} \mathrm{Ar}^{+}$laser line. Figure 9 shows the spectrum of the sample for which the morphology is presented in Figure $3 \mathrm{a}$. This extended spectrum is representative for all undoped and slightly doped layers investigated. According to the measurement done on many locations as a mapping, the layer is $100 \% 3 \mathrm{C}$-SiC. The PL spectrum is dominated by the near-band gap emission $(520-550 \mathrm{~nm} ; 2.4-2.2 \mathrm{eV})$, which contains the nitrogen bound exciton (N-BE) and its phonons replica as well as multi bound exciton lines. Free-exciton related lines have been observed only for the undoped layers. The two phonons replica region is observed around $2.17 \mathrm{eV}$. A weak signal related to $\mathrm{D}_{1}$ center was recorded at $1.97 \mathrm{eV}(628.7 \mathrm{~nm})$. We observed this line for all the investigated samples with a full width at half maximum (FWHM) of about $1 \mathrm{meV}$. Its energy position was slightly shifted from sample to sample between $1.9726 \mathrm{eV}$ for $52 \mu \mathrm{m}$ thick layer to $1.9700 \mathrm{eV}$ for the thinner layer (4 $\mu \mathrm{m}$ thick). No donor-acceptor pair recombination is observed in this extended spectrum (Fig. 9) as well as in all spectra recorded from other layers. The nitrogen concentration is in the range of low $10^{16} \mathrm{~cm}^{-3}$ by measuring the FWHM of the N-BE transverse acoustic phonon $\left(\mathrm{N}_{\mathrm{TA}}\right)^{31}$, doping which also explains why the free-exciton luminescence is rarely observed. The inset of the figure shows the N-BE no-phonon line $\left(\mathrm{N}_{0}\right)$ for three different $3 \mathrm{C}$ epilayers having different thicknesses as well as for a bulk pure single-crystal $3 \mathrm{C}-\mathrm{SiC}$ grown with CF-PVT ${ }^{19}$. For the bulk sample the $\mathrm{N}_{0}$ line is extremely narrow $(\mathrm{FWHM}=0.4 \mathrm{meV})$ which corresponds to the spectral resolution limit of PL equipment at this wavelength. Its energy position at $2.3784 \mathrm{eV}$ is very close to the value reported for bulk 3C-SiC crystal grown by the Lely technique ${ }^{32}$. For our CVD layer the FWHM of the $\mathrm{N}_{0}$ lines is slightly larger with a value of $1.3 \mathrm{meV}$ for the $12 \mu \mathrm{m}$ thick layer. Note that those layers 
were grown with slightly different growth conditions (lower growth rate for the thinner layer) and all with small amount of nitrogen in the gas mixture. For the thicker layer, this no-phonon line is observed at $2.378 \mathrm{eV}$ very close to the bulk value. For the thinner layers, this no-phonon line slightly shifts from the expected position towards low energy. The same energy shift is observed for the phonon replica without discrepancy. Note that for the thinner layer ( $4 \mu \mathrm{m}$ thick) this shift is only of $2 \mathrm{meV}$ towards lower energy compared to the thicker layer. Shifts of $7 \mathrm{meV}$ are typically reported in the literature for $5 \mu \mathrm{m}$ thick $3 \mathrm{C}-\mathrm{SiC}$ epilayer grown on Si substrate ${ }^{33}$ and the width of the $\mathrm{N}_{0}$ line close to $2 \mathrm{meV}^{34}$. The shift is an indication of the internal stress in the layer and the broadening could be related to high doping concentration. Another indication of the stress in $3 \mathrm{C}$ epilayer is given by the relative intensity of the N-BE no-phonon $\left(\mathrm{N}_{0}\right)$, TA, LA and LO lines with respect to the TO line. In stressed epilayer the $\mathrm{N}_{0}$ is seldom observed. Table I lists the corresponding data for three experimental samples of Fig. 9.

\section{Discussion}

From all the experiments, there are apparently two critical issues for obtaining DPB-free 3C-SiC heteroepitaxial layers on (0001) on-axis 4H-SiC substrates:

- A very narrow operating window. Typical growth conditions are $1350^{\circ} \mathrm{C}$ and a $\mathrm{C} / \mathrm{Si}$ ratio of 1 for a pressure of 200 mbar. Even slight variations from those conditions can give rise to DPB formation.

- Specific ramp-up conditions. A carbon-rich surface preparation, either during heating-up or prior to the growth at growth temperature is essential to get DPB-free epilayer. 
In all epilayer deposition processes, in-situ surface preparation prior to the growth is essential as it governs the nucleation of the layer and consequently its quality. It is thus not surprising that for $\mathrm{SiC}$ growth, especially for CVD deposition the in-situ surface preparation is still the topic in many studies. The problem of DPBs reduction has already been tackled, using for instance $\mathrm{HCl}$ for the in-situ preparation of on-axis $6 \mathrm{H}-\mathrm{SiC}$ substrates $^{35}$. (0001) $\mathrm{SiC}$ surface reconstructions have been studied intensively and among the important conclusions, Starke et al.${ }^{36}$ have shown that during the formation of the $(\sqrt{3} \mathrm{X} \sqrt{3})-\mathrm{R} 30^{\circ}$ on hexagonal (0001) SiC, Si rich conditions should promote a cubic sequence to develop at $1000{ }^{\circ} \mathrm{C}$. But this is in apparent contradiction with our observation which evidences that $\mathrm{C}$-rich conditions prior the growth are required to promote high quality $3 \mathrm{C}$ $\mathrm{SiC}$ growth. This puzzling result has to be discussed further.

The experiment presented in Figure 1a shows that at $1325^{\circ} \mathrm{C}$, i.e. only $25^{\circ} \mathrm{C}$ below the optimal temperature of $1350^{\circ} \mathrm{C}$, a SiC $+\mathrm{Si}$ deposit forms on the substrate. This suggests that the gas phase has a silicon excess if the temperature decreases. On the other hand, we observed Si clusters on the sample surface at $1350^{\circ} \mathrm{C}$ when the $\mathrm{Si} / \mathrm{H}_{2}$ ratio is increased (Fig. 2a). After removal of the $\mathrm{Si}$ hillocks by wet chemical etching, we found no deep depression below and the whole $\mathrm{SiC}$ surface was smooth. As the growth was not affected by the presence of these Si clusters, they probably form after the growth during the cooling stage of the reactor (cooling rate is around $20{ }^{\circ} \mathrm{C} / \mathrm{min}$ ) although the silane flux was switched-off. They also can be formed during the growth, however, they may not necessarily affect or stop the growth and contrarily could promote the growth.

The conclusions from these observations are twofold. First, our optimal 3C-SiC deposition conditions are Si-rich and very close to Si condensation in the film. Secondly, there is an additional silicon source in the reactor, even if no silane flux is used. The only reasonable source of silicon is the susceptor itself; large area of the susceptor upstream is loaded with silicon during every 
growth experiments (because the $3 \mathrm{C}-\mathrm{SiC}$ experiments are conducted at low temperature, typically $1350^{\circ} \mathrm{C}$ which is much lower than the typical temperatures used for $4 \mathrm{H}-\mathrm{SiC}$ homoepitaxy). During the temperature ramp-up prior the growth, this extra silicon is vaporized and acts as a Si source. Differently said, the so-called C-rich treatment before the growth (either during ramp-up or at the growth temperature) is actually the nucleation and the growth of a first $3 \mathrm{C}-\mathrm{SiC}$ layer on the $4 \mathrm{H}$ $\mathrm{SiC}$ substrate. For clarity purpose, we will call this first layer "buffer layer" as it governs the occurrence or not of DPBs. At this stage, the conditions of formation of such buffer layer are not clear as the silicon flux coming from the vaporization of a silicon excess upstream is unknown. Nevertheless, some information can be extracted from the experiments.

- The growth rate of this buffer layer is independent on the propane flow rate as the samples of Fig. 3a-c have exactly the same thickness of $15 \mu \mathrm{m}$. The silicon source flux is thus limiting the growth kinetics.

- This buffer layer already forms at lower temperature because the sample of Fig. 3a prepared with propane introduced from room temperature is also free of DPB.

- The propane treatment time at growth temperature is important. Without treatment (Fig. 3d), there is no buffer layer and the layer has many DPBs. After 15 min (Fig. 3e), many DPBs are observed whereas no DPBs are present after only 5 minutes. The buffer layer thus degrades after a while, probably indicating that the Si load consumption could affect the stoichiometry in the gas phase.

At the low temperatures used in this study, it is not surprising to get nucleation of $3 \mathrm{C}-\mathrm{SiC}$. However, it is not clear from the present data why single domain layers can be obtained directly from the nucleation. Additional information as cross sectional observation, would be needed to investigate more in detail the interface $3 \mathrm{C} / 4 \mathrm{H}$, especially in the case of our $12.5 \mu \mathrm{m}$ thick epilayers 
(Fig. 3e, Fig. 7). This is anyway an extreme case. Generally for our thin layers (less than $3 \mu \mathrm{m}$ ) DPBs are observed whereas for thicker layers (more than $3 \mu \mathrm{m}$ thick) DPB free surface is observed. This leads to the discussion regarding lateral growth, where one type of domains can easily over grow the other. Bending of boundaries has been proposed which could depend on the domains size and/or to the lateral (or in-plane) growth rate $^{37}$. High lateral growth rate in specific directions should be applied, which will allow two domains with the same stacking sequence (e.g. ABCABC) to cover a domain characterized with the other stacking sequence (ACBACB). When this occurs stacking fault would be expected at the intersection and this mechanism would give rise to subdomains having the same stacking sequence but slightly mis-oriented or tilted for each other from the [111] direction. These sub-domains are revealed here with the HRXRD (see section IV.3) for the first time, to the best of our knowledge.

\section{Summary}

In this paper, the growth process and detailed characterization of $3 \mathrm{C}$ epilayer on $4 \mathrm{H}$ substrates are studied. We have demonstrated that DPB-free epilayers could be obtained on a large dimension $\left(2 \times 2 \mathrm{~cm}^{2}\right)$ with a standard $\mathrm{SiH}_{4}+\mathrm{C}_{3} \mathrm{H}_{8}+\mathrm{H}_{2} \mathrm{CVD}$ chemistry and without any use of chlorine. It has been found out that a critical point to get DPB-free layer is the occurrence of a buffer layer prior to the growth, formed without any silane injected but using a silicon excess already present in the susceptor. The condition of formation of such buffer layer is unclear and would require specific works. Finally, a thorough characterization of the DPB-free layer is presented. We pointed out the high quality of the $3 \mathrm{C}$ layer. The highest growth rate is up to $5 \mu \mathrm{m} / \mathrm{h}$ for achieving smooth layers with RMS value $<1 \mathrm{~nm}$ for $10 \mathrm{x} 10 \mu \mathrm{m}^{2}$ area. The high purity of the layers is confirmed with PL 
and the lowest net doping concentration is about $2 \times 10^{16} \mathrm{~cm}^{-3}$. The FWHM obtained from HRXRD 2 theta omega curve for a $35 \mu \mathrm{m} 3 \mathrm{C}$ layer of the (111) reflection was only $26 \operatorname{arcsec}$, which denotes high crystal quality material. From the (002) reflection rocking curve, existence of sub-domains is proposed, which could be at the origin of stacking faults observed on the surface of the layers.

\section{Acknowledgements}

Financial support from the Swedish Energy Agency (project 32917-1) is gratefully acknowledged. Mr. Patrick Chaudouet is acknowledged for EBSD measurements and Dr. Ivan Ivanov for assistance in the $\mu$-Raman measurements. 


\section{References}

1. D. F. Ferry, Phys. Rev. B, 12, 2361 (1975).

2. W. E. Nelson, F. A. Halden, and A. Rosengreen, J. Appl. Phys., 37, 333 (1966).

3. A. Schöner, M. Krieger, G. Pensl, M. Abe, and H. Nagasawa, Chem. Vap. Deposition, 12, 523 (2006).

4. R. Cheung, Silicon Carbide Micro Electromechanical Systems for Harsh Environments, Imperial College Press (2006).

5. H. P. Liaw and R. F. Davis, J. Electrochem. Soc., 131, 3014 (1984).

6. T. Nishiguchi, Y. Mukai, M. Nakamura, K. Nishio, T. Isshiki, S. Ohshima, and S. Nishino, Mat. Sci. Forum, 457-460, 285 (2004).

7. S. Leone, F. C. Beyer, A. Henry, O. Kordina, and E. Janzén, Phys. Status Solidi RRL, 4, 305 (2010).

8. J. A. Powell, J. B. Petit, J. H. Edgar, I. G. Jenkins, L. G. Matus, J. W. Yang, P. Pirouz, W. J. Choyke, L. Clemen, and M. Yoganathan, Appl. Phys. Lett., 59, 333 (1991). 
9. L. Latu-Romain, D. Chaussende, C. Balloud, S. Juillaguet, L. Rapenne, E. Pernot, J. Camassel, M. Pons, and R. Madar, Mat. Sci. Forum, 527-529, 99 (2006).

10. M. Soueidan and G. Ferro, Adv. Funct. Mater., 16, 975 (2006).

11. K. Seki, S. Harada, and T. Ujihara, Mat. Sci. Forum, 740-742, 311 (2013).

12. A. A. Lebedev, V. V Zelenin., P. L. Abramov, E. V. Bogdanova, S. P. Lebedev, D. K. Nel'son, B. S. Razbirin, M. P. Shcheglov, A. S. Tregubova, M. Suvajarvi, and R. Yakimova, Semiconductors, 41, 263 (2007).

13. H. S. Kong, J. T. Glass, and R. F. Davis, J. Mater. Res., 4, 204 (1989).

14. M. Soueidan, G. Ferro, O. Kim-Hak, F. Cauwet, and B. Nsouli, Cryst. Growth Des., 8, 1044 (2008).

15. K. Nishino, T. Kimoto, and H. Matsunami, Jpn. J. Appl. Phys., 36, 5202 (1997).

16. F-R. Chen, S. R. Nutt, W. S. Yoo, T. Kimoto, and H. Matsunami, J. Cryst. Growth, 137, 175 (1994).

17. J. Lorenzzi, M. Lazar, D. Tournier, N. Jegenyes, D. Carole, F. Cauwet, and G. Ferro, Cryst. Growth Des., 11, 2177 (2011).

18. P. G. Neudeck, A. J. Trunek, D. J Spry, J. A. Powell, H. Du, M. Skowronski, X. R. Huang, and M. Dudley, Chem. Vap. Deposition, 12, 531 (2006).

19. L. Latu-Romain, D. Chaussende, and M. Pons, Cryst. Growth Des., 6, 2788 (2006).

20. M. Camarda, A. La Magna, and F. La Via, Mat. Sci. Forum, 740-742, 295 (2013). 
21. D. Chaussende, L. Latu-Romain, L. Auvray, M. Ucar, M. Pons, and R. Madar, Mat. Sci. Forum, 483-485, 225 (2005).

22. A. Henry, J. ul Hassan, J. P. Bergman, C. Hallin, and E. Janzén, Chem. Vap. Deposition, 12, 475 (2006).

23. G. Ferro, Mater. Sci. Forum, 645-648, 49 (2010).

24. S. Leone, F. C. Beyer, H. Pederson, O. Kordina, A. Henry, and E. Janzén, Cryst. Growth Des., 10, 5334 (2010).

25. J. Hassan, J. P. Bergman, A. Henry, and Janzén, J. Cryst. Growth, 310, 4424 (2008).

26. A. Boulle, D. Chaussende, F. Conchon, G. Ferro, and O. Masson, J. Cryst. Growth, 310, 982 (2008).

27. R. Vasiliauskas, S. Juillaguet, M. Syväjärvi, and R. Yakimova, J. Cryst. Growth, 348, 91 (2012).

28. J. W. Sun, I. G. Ivanov, R. Liljedahl, R.Yakimova, and M. Syväjärvi, Appl. Phys. Lett.,100, 252101 (2012).

29. P. Hens, V. Jokubavicius, R. Liljedahl, G. Wagner, R. Yakimova, P. Wellmann, and M. Syväjärvi, Materials Letters, 67, 300 (2012).

30. M. Zielinski, M. Portail, H. Peyre, T. Chassagne, S. Ndiaye, B. Boyer, A. Leycuras, and J. Camassel, Mat. Sci. Forum, 556-557, 207 (2007). 
31. J. Camassel, S. Juillaguet, M. Zielinski, and C. Balloud, Chem. Vap. Deposition, 12, 549 (2006).

32. W. J. Choyke, D. R. Hamilton, and L. Patrick, Phys. Rev., 133, A1163 (1964).

33. W. J. Choyke, Z. C. Feng, and J. A. Powell, J. Appl. Phys., 64, 3163 (1988).

34. S. G. Bishop and J. A. Freitas Jr., J. Cryst. Growth, 106, 38 (1990).

35. Z. Y. Xie, J. H. Edgar, B. K. Burkland, J. T. George, and J. Chaudhuri, J. Cryst.Growth, 224, $235(2001)$.

36. U. Starke, J. Schardt, J. Bernhardt, M. Franke, and K. Heinz, Phys. Rev. Lett., 82, 2107 (1999).

37. F. La Via, Silicon Carbide Epitaxy, chapter 9, IBSN:978-81-308-0500-9 (2012). 
Table I. The intensity ratio (in \%) of the N-BE lines to the TO phonon replicas lines for three 3C$\mathrm{SiC}$ epilayers with different thickness $\mathrm{t}$ and for the bulk $3 \mathrm{C}$ sample. The shifts of the line position with respect to that of the bulk $3 \mathrm{C}$ sample $\Delta \mathrm{E}$ is given in $\mathrm{meV}$.

\begin{tabular}{|l|l|l|l|l|l|l|}
\hline Sample & $\mathrm{t}(\mu \mathrm{m})$ & $\mathrm{I}_{0} / \mathrm{I}_{\mathrm{TO}}$ & $\mathrm{I}_{\mathrm{TA}} / \mathrm{I}_{\mathrm{TO}}$ & $\mathrm{I}_{\mathrm{LA}} / \mathrm{I}_{\mathrm{TO}}$ & $\mathrm{I}_{\mathrm{LO}} / \mathrm{I}_{\mathrm{TO}}$ & $\Delta \mathrm{E}(\mathrm{meV})$ \\
\hline 1 & 4 & 20 & 41 & 67 & 73 & 2.5 \\
\hline 2 & 12 & 23 & 40 & 65 & 76 & 1.5 \\
\hline 3 & 52 & 24 & 41 & 64 & 77 & 0.5 \\
\hline bulk & 2000 & 23 & 41 & 84 & 69 & \\
\hline
\end{tabular}

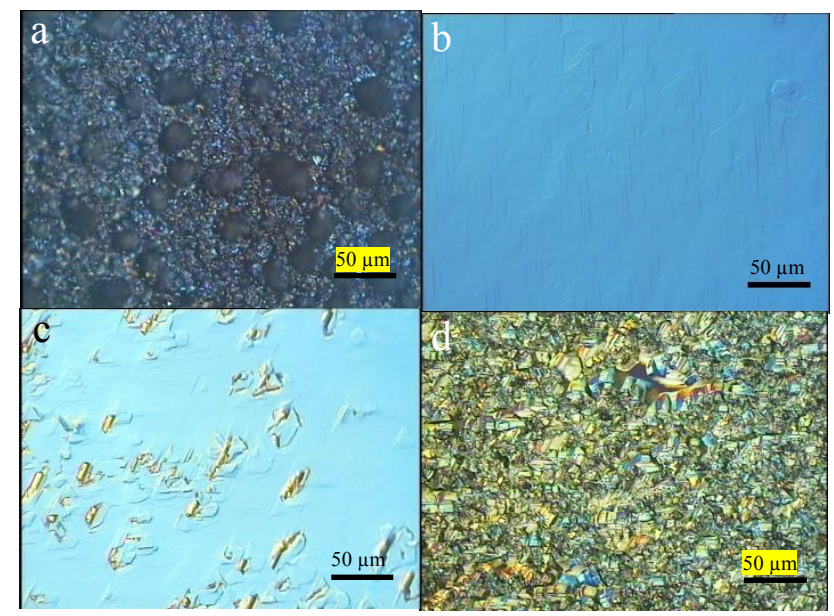

Figure 1. NDIC images of $3 \mathrm{C}$ epilayers grown at (a) $1325^{\circ} \mathrm{C}$ (b) $1350^{\circ} \mathrm{C}$ (c) $1375^{\circ} \mathrm{C}$ (d) $1400{ }^{\circ} \mathrm{C}$ with a fixed $\mathrm{C} / \mathrm{Si}=1, \mathrm{Si} / \mathrm{H} 2=0.02 \%, \mathrm{C} / \mathrm{N}=0.32 \%$ and the same $\mathrm{C}$-rich ramp-up conditions. The thickness is approximately $20 \mu \mathrm{m}$ for all the epilayers except $12 \mu \mathrm{m}$ for the one in (c). 


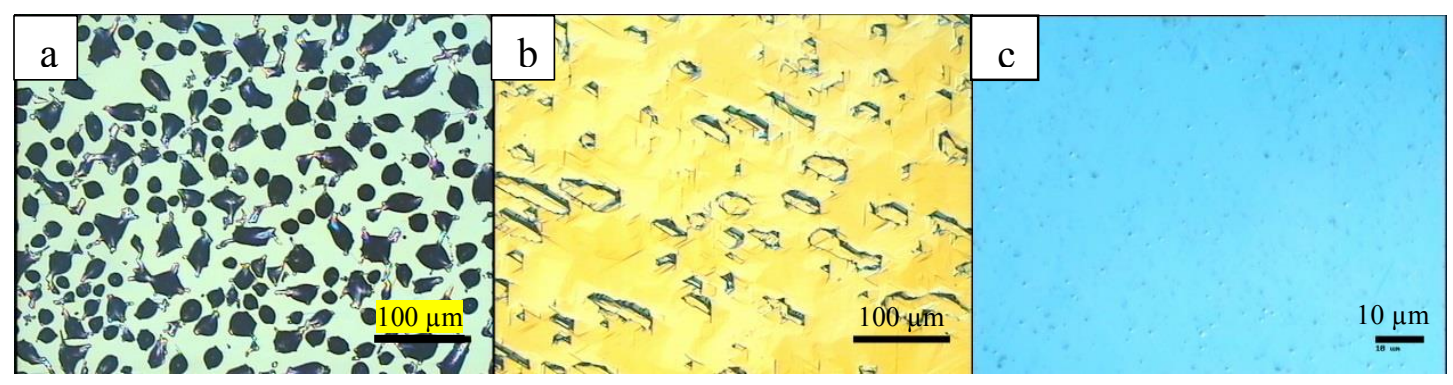

Figure 2. Optical microscopy images of $3 \mathrm{C}-\mathrm{SiC}$ epilayers grown at $1350{ }^{\circ} \mathrm{C}$ with the same C-rich ramp-up condition, but at different $\mathrm{C} / \mathrm{Si}$ ratios (a) 0.9 (b) 1.1. The thickness of these layers is about $19 \mu \mathrm{m}$. The $\mathrm{Si} / \mathrm{H} 2$ ratio is (a) $0.022 \%$ and (b) $0.019 \%$, respectively. (c) shows the surface morphology of a layer similar as in (a) but after wet chemical etching in $\mathrm{HNO} 3: \mathrm{HF}: \mathrm{CH} 3 \mathrm{COOH}=$ $5: 3: 3$ 


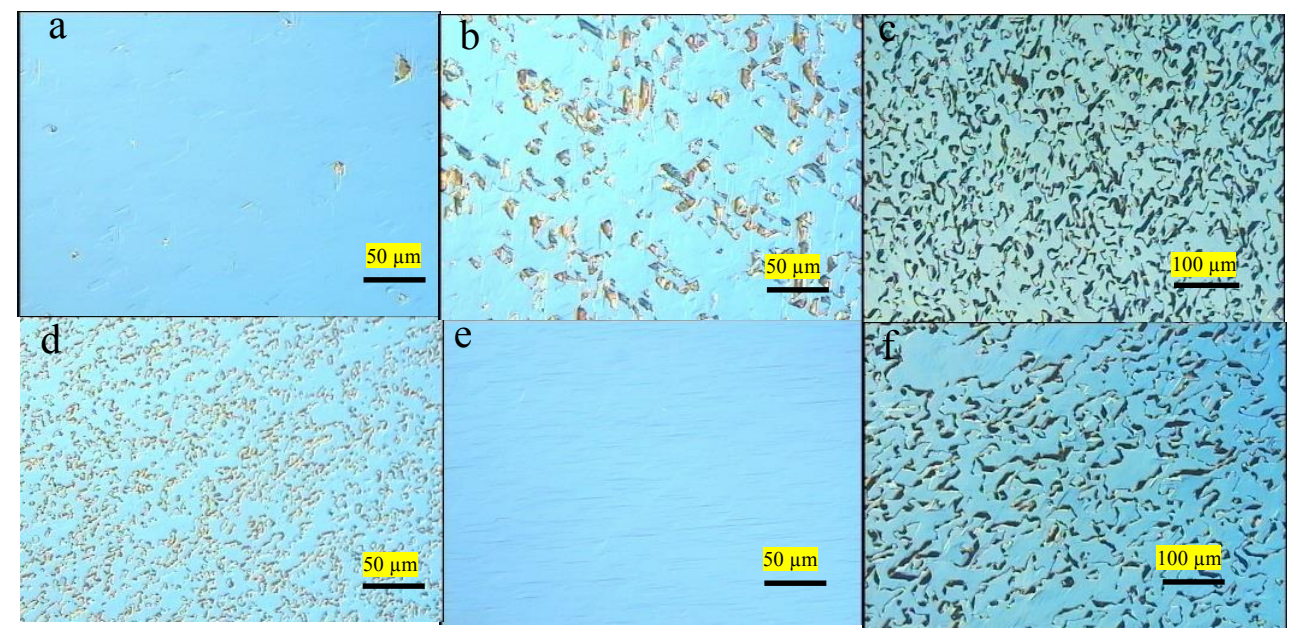

Figure 3. NDIC images of 3C-SiC epilayers with different ramp-up conditions. Different $\mathrm{C} 3 \mathrm{H} 8$ flow rates of (a) $0.015 \%$ (b) $0.043 \%$ (c) $0.1 \%$ in $\mathrm{H} 2$ are used from room temperature to growth temperature. For (d)-(f), the ramp-up is performed under $\mathrm{H} 2$ and once the growth temperature is reached, a $0.015 \% \mathrm{C} 3 \mathrm{H} 8$ in $\mathrm{H} 2$ treatment is conducted prior to the growth with varying times: (d) 0 min (e) 5 min (f) $15 \mathrm{~min}$. All these ramp-up conditions are followed by the same growth step, experiments were done at $200 \mathrm{mbar}, 1350{ }^{\circ} \mathrm{C}, \mathrm{C} / \mathrm{Si}=1, \mathrm{Si} / \mathrm{H} 2=0.015 \%$. Only the growth time could vary, between $1 \mathrm{~h}$ and $4 \mathrm{~h}$, giving a film thickness comprised between $4 \mu \mathrm{m}$ to $16 \mu \mathrm{m}$. The growth rate is constant of $4 \mu \mathrm{m} / \mathrm{hr}$. 


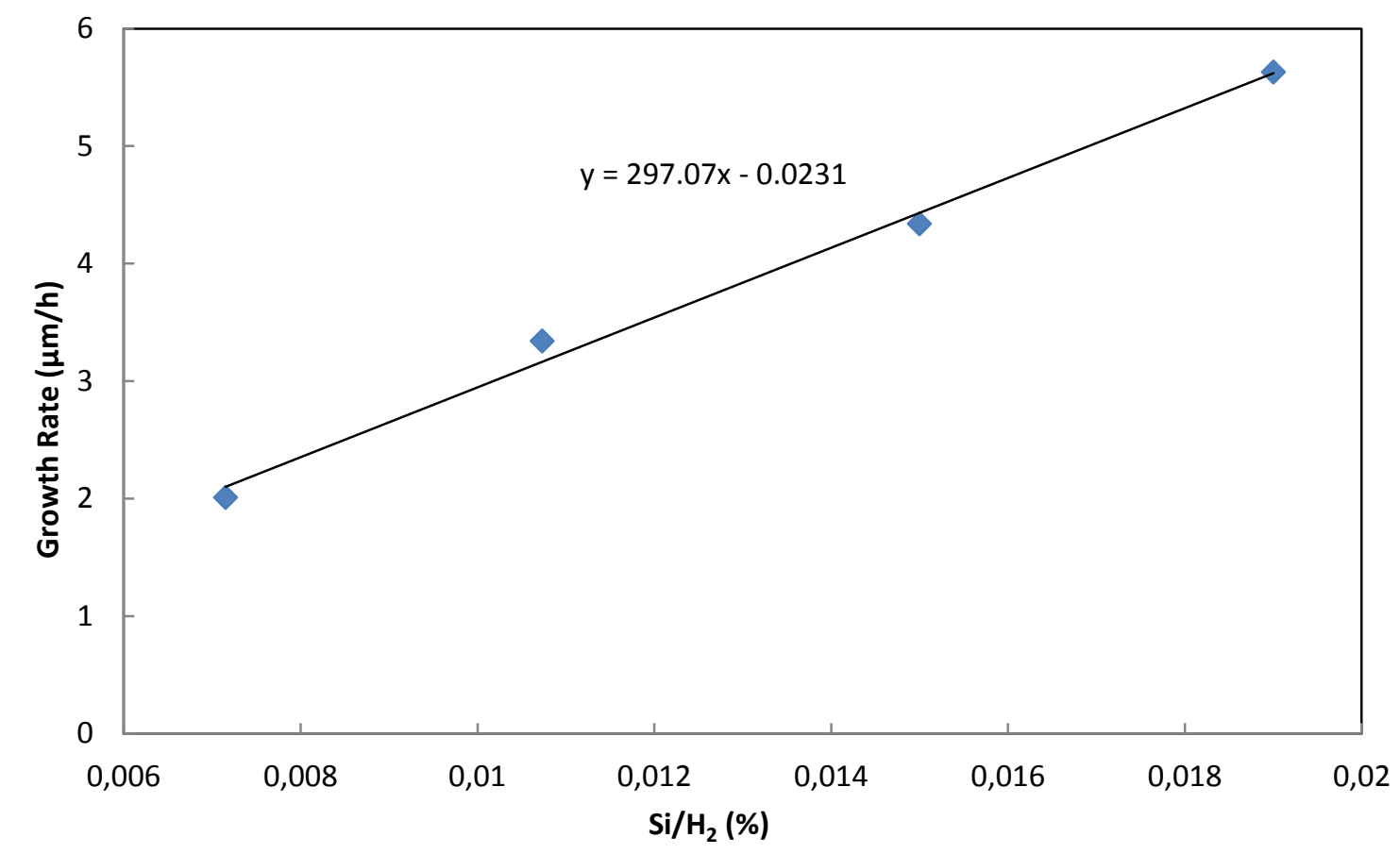

Figure 4. Growth rates for various silicon molar fractions. The growth runs were done at $1350^{\circ} \mathrm{C}$, $200 \mathrm{mbar}, \mathrm{C} / \mathrm{Si}=1, \mathrm{C} / \mathrm{N}=0.32 \%$. The insert line is the linear trend of these points.

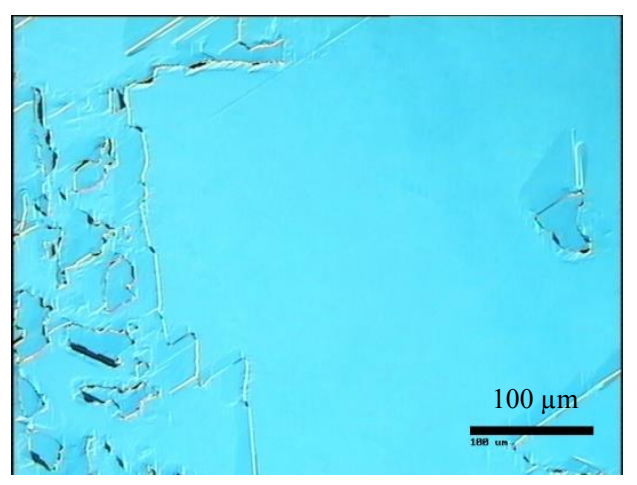

Figure 5. 3C-SiC on $6 \mathrm{H}-\mathrm{SiC}$ substrate performed at $1350{ }^{\circ} \mathrm{C}, 200 \mathrm{mbar}, \mathrm{C} / \mathrm{Si}=1, \mathrm{Si} / \mathrm{H} 2=0.015 \%$ and C-rich ramp-up condition. 

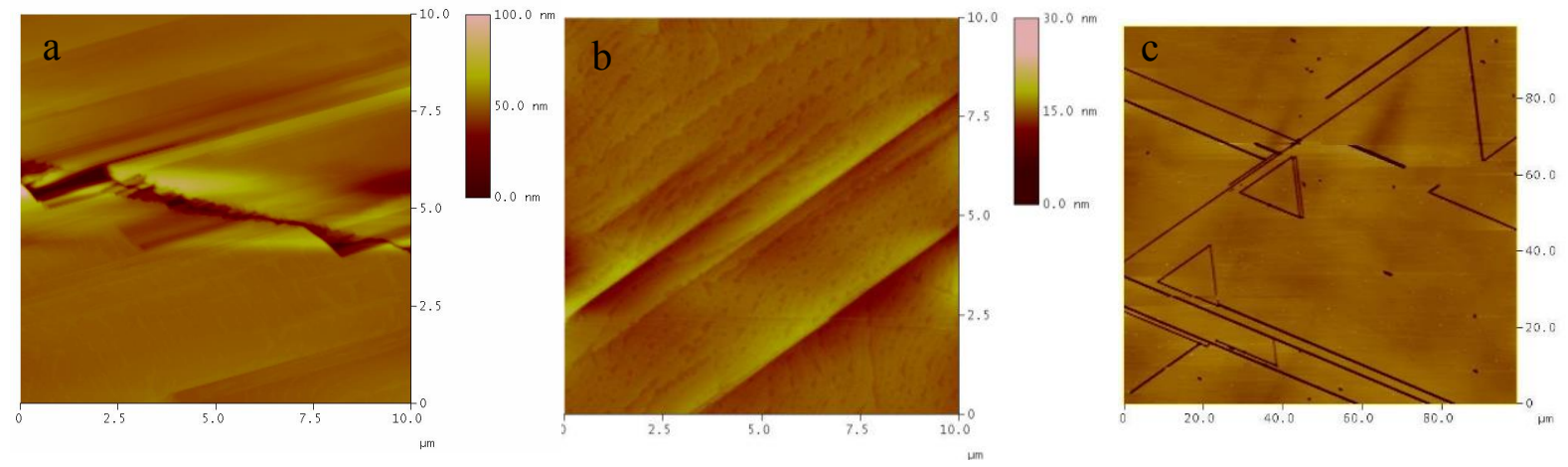

Figure 6. 10x10 $\mu \mathrm{m} 2$ AFM top view images of (a) a boundary between two domains of a $20 \mu \mathrm{m}$ thick 3C sample with DPBs, (b) the same sample as in Fig. 3e and (c) 100x100 $\mu \mathrm{m} 2$ AFM top images of a single domain sample after $\mathrm{KOH}$ etching. 

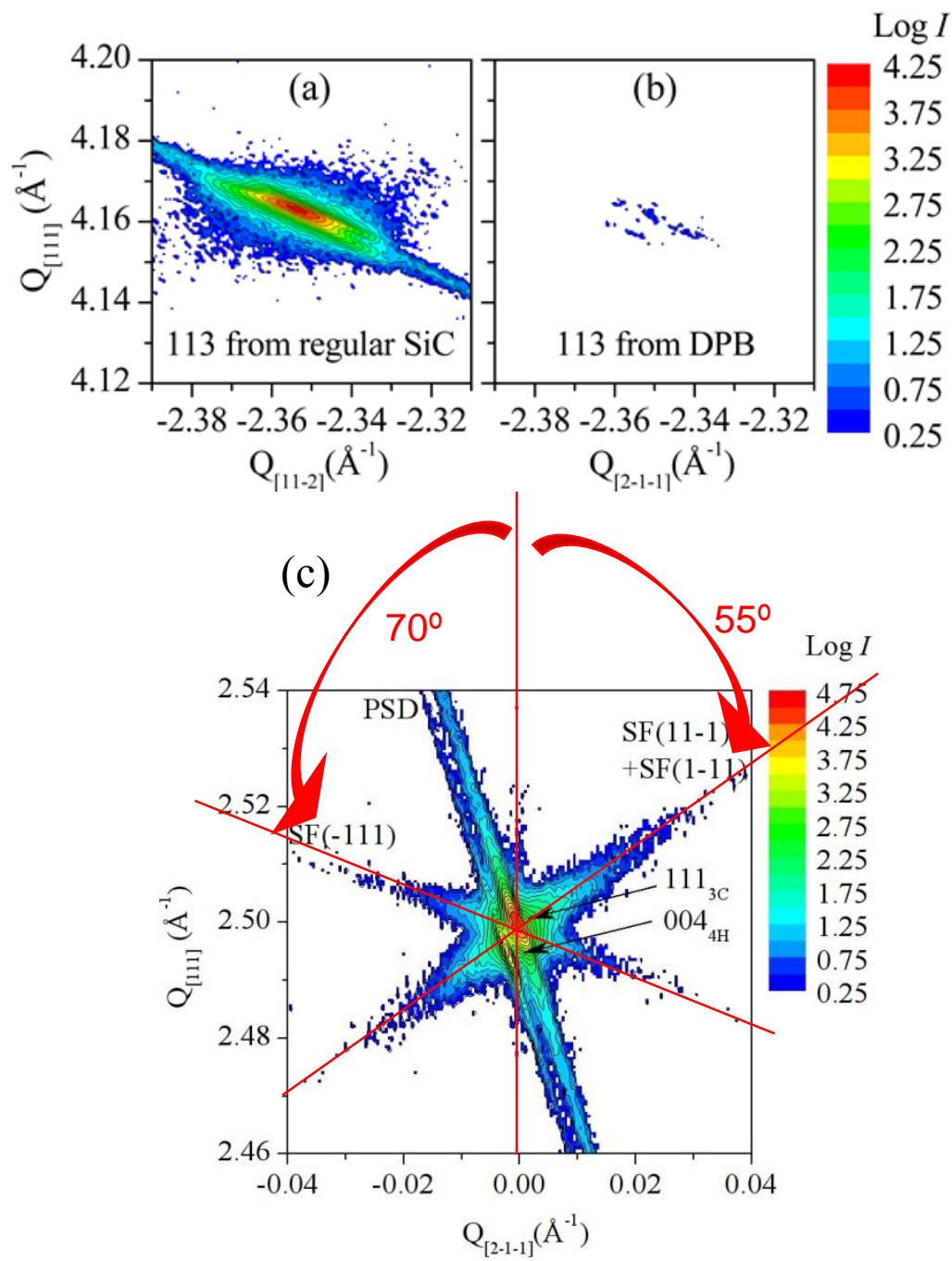

Figure 7. Reciprocal space maps for a $12.5 \mu \mathrm{m}$ thick epilayer of the (a) (113) diffraction peak for maximum intensity, (b) (113) diffraction peak after $60^{\circ}$ rotation around the crystal symmetry axis and (c) (111) diffraction peak. 

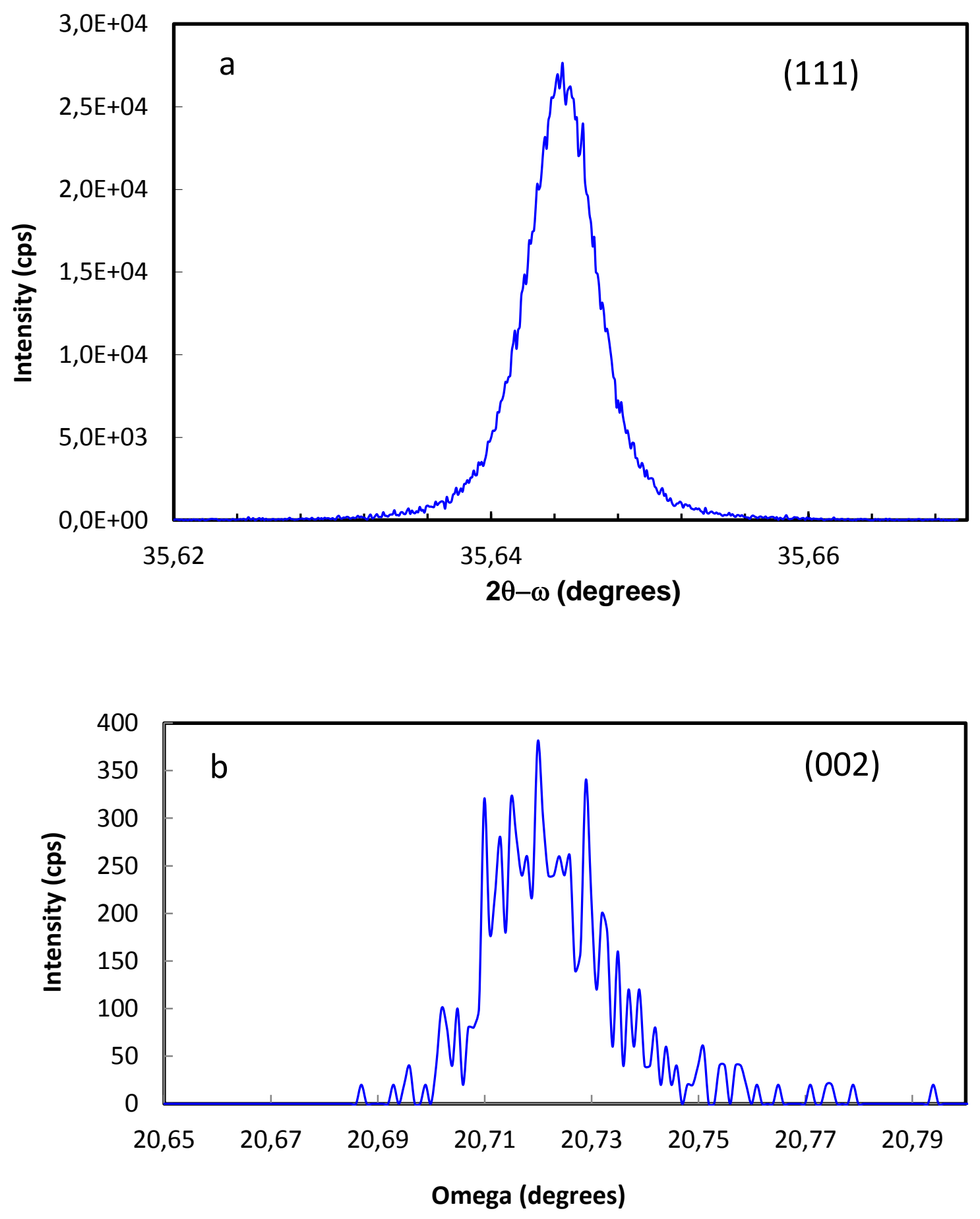

Figure 8. (a) 2 $\theta-\omega$ HRXRD spectrum of (111) reflection and (b) rocking curve of (002) reflection for a $35 \mu \mathrm{m}$ thick $3 \mathrm{C}$ on $4 \mathrm{H}-\mathrm{SiC}$ epilayer. 


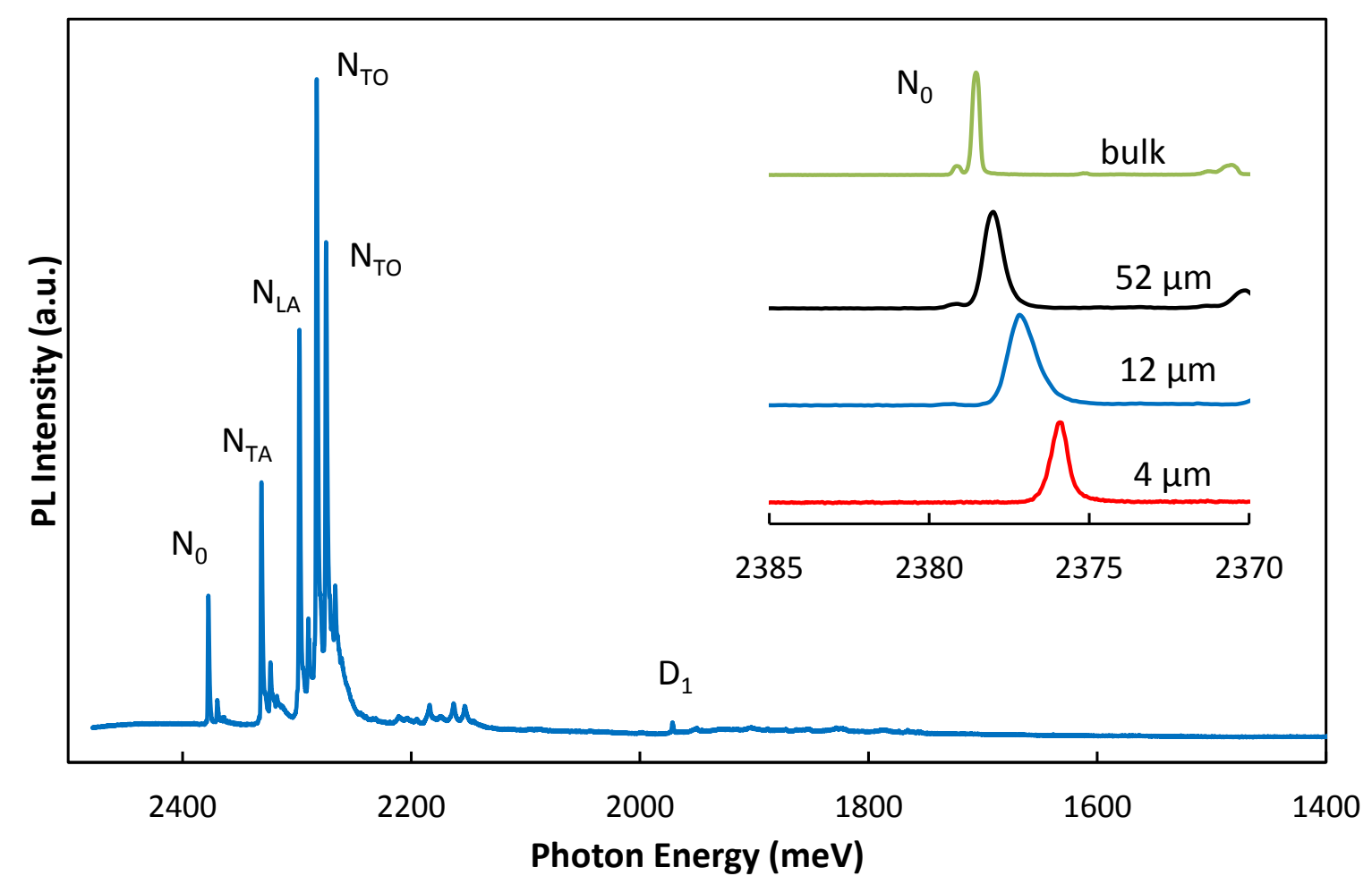

Figure 9. LTPL spectrum at $2 \mathrm{~K}$ of the same sample as in Fig. 3e. The inset shows the near-band gap emission for three different layers with the indicated thickness together with the recorded spectrum from a bulk 3C sample. 